\title{
Analysis on Mo Yan's Literature from International Perspective
}

\author{
Lihua Yang \\ Heihe University \\ Heihe, China 164300
}

\author{
Zhichun Zhu \\ Heihe University \\ Heihe, China 164300
}

\begin{abstract}
According to the abroad spreading scale and influence of Mo Yan's works, it will naturally become one of the representatives for overseas to research Chinese contemporary literature. The author found a basic law when referring and classifying materials: If writers wrote a lot of books and his works were translated into kinds of languages and were reprinted for many times, they must have many research results and these writers were excellent writers. There are many papers researching works of Mo Yan in British, French, German and Japanese. Limited by language ability, the author only analyzes part of representative English research briefly in this paper.
\end{abstract}

Keywords-international perspective; Mo Yan; literary world

\section{INTRODUCTION}

Mo Yan and his contemporary local writers have ideological cosmopolitanism background while are rooted in history life of local community. They are concerned about the change of reality. They are closely linked with farmers who are oldest and most numerous in China from the blood to the destiny. What's more, they both have received modern education. They met history turn of reform and opening up when they are young and they are dipped by the most advanced artistic ideological trends and are exposed to exotic cultures. What they learn abroad constitutes intercultural writing horizons, they think Chinese and rural problems in the comparative reference. For them, China is a part of humanity and the fate of farmers is part of the destiny of mankind. Compared to the previous generation of local writers, they are cosmopolitan so they completely excess the narrow class theory, sociology and nationalist ideology, not mention the constraint of politic parties. The basic problem of humanity was fully showing in personalized way in of their art world, such as food, sex, reproduction, death, war, race, wealth, power, all kinds of violence, civilization, father and son, nature and civilization, person and history, truth and lies, as well as the ecological environment, development and faith and findin0g their homes and so on, which makes the universal values specific and vivid. However, Mo Yan represents his own thinking in a full feeling way, he swept away the stiff dykes of historical logic, and led off tremendous pain and joy of the soul in explosive-like unrestrained language, nourished a variety of life style legend in the grafted test of Chinese and foreign languages, showed a mythical thinking by art exhibits and established his own simple but magnificent poetry land.

Fund project: - Comparative research on works of Herta $\cdot$ Muller and Mo Yan from the perspective of Nobel Prize, Heilongjiang province philosophy and social sciences planning project No. $13 \mathrm{C} 033$

\section{MO YAN'S LITERARY FIELD}

Global extends of "Mo Yan hot" blotted out a "China Color" in the world literature heavily and created favorable external conditions for the "world horizon" of Chinese Literature Research. In 2013, there are many seminars centered on Mo Yan in China, such as the "Nobel Prize for Literature and China: from Lu Xun to Mo Yan" (Beijing), "From Tagore to Mo Yan: the World Significance of century oriental culture" (Shanghai), "Mo Yan • Nobel • Chinese Contemporary Literature" Forum (Xiamen), "Local Complex in Mo Yan works" (Gaomi).....Bai Ye said in do a witness of literary advances with the times that, "when compiling Chinese literary Chronicle this year, we have classified some sort of focus phenomena of intentionality and the investigation of Chinese experience caused by Mo Yan winning Nobel Prize deserves adequate attention.

In 2013, the concept Chinese dream which was rich in literary color was promoted a kind of Chinese spirit. Literary studies on Chinese dream and Chinese characteristics have achieved a lot. Take Journal of Literature and Art as an example, papers such as "China Dream and cultural power construction", "Chinese dream and Rise of science fiction", "using literary criticism power to boost China Dream", " worker literature and the Chinese workers' Literature Dream" ," Chinese dream and literature dream " and "Chinese dream of Literature" in this year drew a lot attention. In addition, discussions on "Chinese Story", "Chinese characteristics", "Chinese spirit" and "Chinese experience" were still ongoing. Another concept related to this is the "Chinese Literary Geography". The concept, put forth and described by Mei Xinlin and so on, begun to boost after years development. Academic papers interpreting literary works from geography have been commonly seen. Similar new concepts, new methods are emerging, indicates that literary studies remain a strong sense of discipline and positive innovation.

\section{OVERSEAS INFLUENCE OF MO YAN}

Mo Yan's works that are translated into English are Red Sorghum, Paradise Garlic Song, The Republic of Wine, Big Breasts and Wide Hips, Life and Death Fatigue, Master is increasingly humorous and "explosion" and were mainly translated by Ge Haowen, who is known as chief translator of modern literature. Researches on works of Mo Yan are 
published on many famous journals such as Chinese Literature, Modern Chinese Literature and Culture (former Modern Chinese Literature), World Literature Today, Modern China, China Information, Journal of Modern Literature in Chinese,

Positions. Of course, there are many comments on Mo Yan and his works in various newspapers media. Foreigners study Mo Yan from different angles and it can be divided into the following categories from the title: such as the analysis on "Red Sorghum" and "The Republic of Wine", it counts most in studies. They usually find a theme from works to research: comparative study, such as Guptak's and Suman's study between Mo Yan and Li Rui, Kong Haili's study between MoYan and Duanmu Hongliang, Wang Dewei's Imagic homesickness and papers of Fang Jincai. Another type can be broadly classified as integrated or comprehensive study, such as Wang Dewei's Mo Yan's literary world, Liu Yiran's and , Michael Duke's papers. Among these researches, most of the comments are on Red Sorghum, Big Breasts and Wide Hips and The Republic of Wine.

\section{Overseas Scholars' Research PERSPECTIVE}

Wang Dewei, Now a professor at Harvard University, said in Mo Yan's literary world that, Mo Yan mostly discusses questions in three areas in his works: one is the possibility of history imagination space; another is about the complex relationship between narrative, time and memory; the rest is to redefine the subjectivity of politics and sexuality. The paper argues these questions from his five novels and some famous novella and launches a demonstration that Mo Yan completed the transformation of three directions, they are: from heaven to the latrine, from official history to unofficial history, from subject to body. No characters in Mo Yan's works conform to people built by Mao Zedong who are glorious and correctly "red" people. These common people with layman desires and laity emotions are the challenge for the Maoist dogma. When it comes to Red Sorghum, he says, "we heard (or saw) narrator riding in the field of history, memories and fantasies. Through the dense red sorghum, he peeped at 'my grandfather,' 'my grandmother' erotic encounter ... Past and future, desire and fantasy, all of a sudden turned into a scene of flesh and blood in his novels". At the last of the paper, the author pointed out that the reason why he always mentions "history" is that he believes it is essential power to promote the novels of Mo Yan popularized in the world. It also objectively proved the endeavor that he tries to replace by imagination in novels. Mo Yan spares no effort to mix his narrative style and form, which is the most powerful weapon for him being involved in the construction of history dialogue.

Thomas M. Inge, once was professor in Virginia Randolph - Macon College Department of English, thinks high of Mo Yan's works. At the beginning of Mo Yan in eyes of Westerners, he said, "Mo Yan is expected to enter a broader stage of world literature in the twenty-first century as a worldclass writer". Article mainly analyzes the Red Sorghum, Paradise Garlic Song and The Republic of Wine the three works. He considers Red Sorghum creates a magical home. The whole novel is of an epic quality and the innovative narrative subverts the authenticity of the official history and simply demonizes Japanese aggressors. The author's opinion is soaked in the creation and creates a full, complex character. All of these are important factors in this work to achieve success. He believes that Mo Yan has created a number of unique and interesting works, which are not only beneficial to China Contemporary Literature but maintain their own aesthetic principles. Mo Yan devotes him to the process that Chinese literature steps into world literature actively. He said more than one critic agrees the opinion of Professor Michael Duke in University of British Columbia in Canada: that is, Mo Yan is increasingly showing his potential of being a real great writer". Michael Duke appreciates Mo Yan's Paradise Garlic Song much. He thinks this book combined skill and thematic together and created a unique and moving mature works of art with profound ideas. It is the most thoughtful Text of Mo Yan, it supports the reform but without any special political factors. It is one of the most imaginative works with artistic attainments among Chinese novel in twentieth century, which reappears complexity of peasant life image. In this work, perhaps Mo Yan enters more deeply and systematically into the hearts of Chinese farmers deeply than any other Chinese writers who wrote the theme of rural Chinese writers in the twentieth century, led us to understand their feelings and life.

\section{REVIEW OF MO YAN'S LITERATURE}

As René Wellek put it, "The full meaning of a work of art cannot be only defined by view $\mathrm{s}$ of its author and his contemporaries. It is the result of cumulative process and the result of generations of countless readers' critic on the works". According to incomplete statistics, up to 2012, monographs of master focused on Mo Yan's works are 158 and that of doctor is 9. Papers analyzing the folk connotation and value Mo Yan's works from the "folk" perspective weigh highest and dig deepest. Owing to folk position and attitude of Mo Yan, whether his works are irradiative or not is judged by these in a lot of papers. In terms of reflection on history in Mo Yan's works, as well as the appreciation on image, spirit and cultural connotation, they are also hot topics. The authors describe writing style of Mo Yan from some of these theoretical hot topics such as sensibility, ugliness-appreciation, strangeness, hilarity and polyphony, or monograph Mo Yan language features, the use of images, or discuss Mo Yan' overall narrative style and strategy from the perspective of narrative linguistically. There are also many papers that describe works of Mo Yan from the overseas influence and comparative studies. Among them that research Mo Yan in Vietnam counts most. Papers comparing Mo Yan with Kenzaburo Oe, Faulkner, Marquez, Lu Xun and Shen Congwen are of higher quality. Generally speaking, these papers focus on correct hot topics and appreciate text in detail. They research deeply with a wide research field. But when enriching and expanding the research of Mo Yan, there are also relatively little classic papers. Their theoretical explanation is weak and repeated. Problems such as integrity research, thoughtful research and regional research on Mo Yan's works need to be further explored. 


\section{INHERENT BASIS FOR INTERNATIONALIZATION OF MO YAN'S NOVEL}

The value represented in works of Mo Yan is the current and contemporary. It brings some thoughts for the way of Chinese literature stepping into the world. First of all, world literature is dialogue under the "literary" architecture. After analyzing that current western literature research turned into theory age in 1960s in the coming of the era of world literature, Zhang Longxi had two inclinations associated with world literature: "The first is the strong self-critical tendency of western literature and cultural theory, which makes western scholars criticize centrism sharply". "The second result of western literary and cultural criticism in the last twenty years of development is that literature is gradually replaced by theory, which leads to profound 'identity crisis' in the research of literature". While this theoretical criticism also influenced contemporary Chinese literature study. From the internationalization of Mo Yan's works we can find that we can use kind of key words in western thoughts to conclude features of criticism on Mo Yan. While these key words can be used to analyze any countries all over the world. Does this mean excess explanation? Does this mean instrumental of thoughts criticism, use works to show off theory? A deeper problem is the crisis of literature. The subjectivity is hidden by thoughts, therefore, Zhang Longxi puts forth valuing the literary of world literature to avoid the identity crisis of comparative literature: "in the eye of the author, the study on world literature which has drew increasing attention recent years is one process to return to past, it is a new research direction, especially for future development of comparative literature. To solve the identity crisis, we must return to past, it is an inexorable trend; while breaking traditional limitation of European centrism makes this return not any longer pure European and American literature, but real world literature, which opens a new field for literature study.

\section{CONCLUSION}

The overseas acceptance of Mo Yan' works explained that with the overall rise of contemporary China in international status, Chinese writers are more and more noticed and researched by the world and that contemporary Chinese writers have strength in different cultural fields to attract more readers in order to promote the development of world literature and culture. For overseas criticism from a variety of perspectives and voices, our domestic readers and scholars must take dialectical attitude to learn with the objective identification. Only in this way can we promote the healthy development of domestic critics better and promote international academic communication and exchange.

\section{REFERENCES}

[1] Zhang Xuejun. Mo Yan's novels and western modernism literature[J]. [J]. Qilu Journal, 1992(4):26-32, 1992(4): Page 26-32

[2] Zhang Jing. Ppread and acceptance of mainstream American newspapers to Mo Yan's novel under framework theory perspective[J]. Contemporary Writers Review, 2015(3): Page 166-179

[3] Li Bo. Creation of Mo Yan's novels under postcolonial context[D]. Shandong University, 2013. 